\title{
The Developmental Process of Managing Virtual Training for Teachers
}

\author{
Rafiza Abdul Razak, Farrah Dina Yusop, Yugendran Perumal, and Sri Raman Chukumaran
}

\begin{abstract}
This paper explores the developmental process of managing virtual training for 120 teachers from three different schools. Training session's wereadministered in two phases: authentic environment andface-to-face virtual environment. Observation and content analysis were the two techniques employed in collecting the data. The outcome of the research was production of a system for managing virtual training for teachers.
\end{abstract}

Index Terms-Virtual training, technology training, instructional materials, ICT com petencies.

\section{INTRODUCTION}

The British Educational Communications and Technology Agency [1] listed 7 barriers for teachers wishing toutilize and implement information and communication technologies (ICT). They are: 1) lack of teacher confidence and teachers' computer anxiety; 2) lack of teacher competence in using technological tools and software; 3) lack of access to resources; 4) lack of time forreceivingICT training; 5) technical problems faced during technology implementation sessions; 6) teachers' resistance to change and other negative attitudes; and 7) teachers' lack ofperception of the benefitsof integrating technology into teaching and learning.

Similar research on barriers to ICT implementation in a Malaysian school context by [2] echoes[1]'s report and reportsadditional barriers that includelargeclass sizes, facility limitations, lack of real-life technological support for teachers, and heavy administrative loadsthat hinder teachers from focusing on improving their teaching practices.

From the perspective of teachers' continued professional development (CPD), these barriers to technology integrationcan be further categorized into internal and external barriers.Internal barriersin this paper refer to intrinsic barriers related to the individual teacher, includingperceptions and attitudes towards technology integration for teaching and learning such as lack of confidence in using technology, computer anxiety, lack of competence, resistance to change, negative attitudes towards technology, and perception of no technology benefits. These barriers could be reduced or overcomeby changing eachindividual teacher's perceptions and attitudes.

Manuscript received December 12, 2013; revised June 26, 2014. This work was supported by the University of Malaya Research Grant No.RP002C-13ICT.

Rafiza Abdul Razak, Farrah Dina Yusop, Yugendran Perumal, and Sri Raman Chukumaran are with the Department of Curriculum and Instructional Technology, faculty of Education, University of Malaya, Kuala Lumpur, Malaysia (e-mail: rafiza@um.edu.my, farah@um.edu.my, yugen_2004@siswa.um.edu.my, sriramannair86@gmail.com).
External barriers on the other hand refer to all extrinsic factors,both at the school and national level,hindering teachers from integrating technology into the classroomand over which teachers have no direct power and authority to control,. Examples of school-level barriers are lack of access to resources, facility limitations, and lack of access to real-life technological support.

National-level barriers in this paper refer to characteristics of the overall design of the educational system itself. These barriers are especially evidentincountries that implement centralized educational systems in which the federal government specifiesanational curriculum, syllabus, and delivery system. Examples of suchbarriers include exam-oriented educational systems, largeclass size, and heavy administrative loads. Given these barriers, one question arises: how canthese barriers be removed or at least minimized to assist in technology integration in curricula? Echoing other scholars' arguments [3]-[6], we strongly believe that these barriers are inter-related in nature, i.e.,one barrier could potentially lead to another. As [1] reported, lack of technological access potentially results in lack of teacher technology competence. Similarly, it can potentially contributetowards teachers' lack of confidence inusing technology forteaching and learning.

The complex inter-relationships between these barriers, however, do not implythat nothing can be done in terms of teachers' continued professional development. We argue that teacher trainers should focus more on removing, or at least minimizing, the internal barriers to technology integration because they are much more manageable and controllable than the external barriers. Accordingly, what are the important elements a teacher trainer should consider when designing ICT training for teachers? The next section of this paper will review some aspects of effective training reported in scholarly literature.

\section{REVIEW OF RELATED LITERATURE}

\section{A. Teachers and ICT Competencies}

Ref. [7] highlights six important elements: policy and vision, curriculum and assessment, pedagogy, organization, teacher professional development, and ICT, as guidelines for enhancing professional development for teachers. Each element demands ICT skill if teachers are to further enhance their professional skills. Policy and vision focuses on technology literacy, knowledge deepening, and knowledge creation. Curriculum and assessmentincludes basic knowledge of technology, knowledge application, and $21^{\text {th }}$ century skills. Pedagogy highlights technology integration, complex problem-solving, and self-management. ICT 
includes basic, complex, and pervasive ICT tools. These elements further assist organizational efforts to improve on classroom standards and create collaborative groups and learning organizations.Digital literacy predominantly helps to manage and provide guidance for teachers' professional development.

An approach has been designed to integrate ICT into professional development for teachers. It describes a new strategic approach in training for teachers ([8] and [9]) comprised of four different stages. The first stage is described as having traditional, emerging, and technology add-on elements, and technology is perceived in this stage as acomponent added to traditional curricula. The second stage involves transmission, application, and technology literacy.Teacher training in this stage focuses on the development of digital literacy and the use of ICT for professional development. The third stage highlights transition, infusion, and knowledge-deepening. In addition, teacher professional development in this stage should focus on ICT utilization in guiding students through complex problems and thereby manage a dynamic learning environment. The fourth stagefocuses on transformation, and knowledge creation. Teachers in this stage are perceived as knowledge producers constantly engaged in producing new knowledge about teaching and learning [7].

Utilizing digital application for instruction enables teachers to practice higher-order thinking and decision-making skills. Digital application advocates instructional processesthat produce effective learning in a contemporary society [10].

Ref. [11] explains that there is a positive relationship between teachers' competency levels and their confidence in usingICT. Hence teachers with high confidence level in using ICT tend to believe that technology in ICT is useful in developing effective instruction if appropriately applied.

\section{B. Effective Technology Training}

A Professional Development Framework for E-learning aimed at developing the ability of staff to select anduse appropriate e-tools and techniques to support and enhancedelivery of the curriculumhas beendeveloped [12]. This framework includes:

- developing critical analyses of the potential applications of e-learning tools and techniques

- developing capability in introducing new teaching and learningtechniques and tools, including selecting applications, designingblended learning programs, planning, and evaluation

- developing teaching, mentoring, and leadership skills to support an e-learning environment

- encouraging practitioners to reflect on their practice

- enablingcareer progression through acquisition of new skillsand accreditation.

The topic of effective technology training has been discussed quite extensively in the literature. Some of itsaspects that contribute toward its effectiveness are discussed below.

\section{1) A mix of training providers}

Each training provider approaches training differently. Some are verytechnicallyoriented while others are much more pedagogicallyoriented. Effective training should balance both approaches to provide maximum benefit. Additionally, each training provider will have his or herown preferred style and training format,leading to considerable variationinconforming to individual teachers' preferences, styles, and needs [13].

\section{2) Appropriate time for training.}

Because teachers are occupied with various teaching and administrative duties, they may have very limited time to nourish their own personal development. Research on teachers' ICT training in countries like the UK, Australia, and the USA suggests the importance of providing non-contact time for training during school hours [1]. This suggestion stems fromthe reported lack of personal time to learn technology becauseteachers spend muchof their time teaching and attending parent and staff meetings.

Reflecting on the Malaysian context, [2] noted that Malaysian teachers are very much more occupied with administrative than withinstructional tasks. They reported that Malaysian teachers are responsible for virtuallyevery aspect of students' lives in school, including collecting school-related fees, contacting parents in the eventof students' absences, various record-keeping tasks including monthly, mid, and final exam records, accompanying students' to sports competitions and various social events like performances and meetings during special celebration days, and bringing students to clinics or hospitals in cases of unexpected illness, to mention just a few such tasks.Having a non-contact time for ICT training therefore may be seen as an added and unfair burden to teachers unless school administrators agree to free teachers from some of these duties and transfer suchburdens to school administrative staff members.

\section{3) Stages of training}

Several scholars focusingonthe field of instructional design haveprescribed a variety of approaches and models forachieving effective training. The most recognized approach is [14] Gagne'snine events of instruction.[14] proposes that teaching should be delivered in the following consecutive stages: gain attention, present objectives, stimulate recall of prior knowledge, present content, elicit performance practice, provide informative feedback, assess performance, and enhance retention and transfer.

Withregard to technology training, [14]'s nine events of instruction maybe illustrated as follows: trainers should first gain participants' attention before introducing the instructional objectives of the training. Instruction should begin by stimulating a recall of participants' prior knowledge related to the training content they are aboutto learn. Next trainers should present content using a variety of appropriate instructional approaches supported with a variety of practices and informative feedback. Trainers should finally design a performance test forassessing participants' understanding of the content presented earlier and proceed to enhance their information retention and knowledge transfer.

Content- and delivery-wise, scholars such as [15] suggest that training should first emphasize anunderstanding of the basic features and functions of the technology, then move forward to examples of its application ina teaching and 
learning environment. This is to ensure that teachers understand both the technological and the pedagogical components of technology integration. Similarly, [16] recommends that trainers shoulddeliver training based on individual teachers' experiences and skills with respect tothe computers and particular technology to be introduced. Variation in levels of training is important to ensure that the training conforms toindividual teachers' needs.

Considering these important elements, the Me-CPD (Managing Electronic Continued Professional Development) modelwas designedto be a hybrid of managing face-to-face and virtual trainings. The next section of this paper describesdesign and implementation of this model

\section{Methodology}

This research employed qualitative methodology in investigating the developmental process of managingvirtual training for teachers.The research specifically utilized content analysis and observation techniques. The procedure of developing virtual training for teachers was examined step by step.

\section{A. Observation}

Step 1: Face-to face training.

As a preliminary session prior to the virtual training, teachers went through a face-to face training session. At this stage, teachers were exposed to e-CPD (electronic continued professional development) utilization and applicationin an authentic environment.

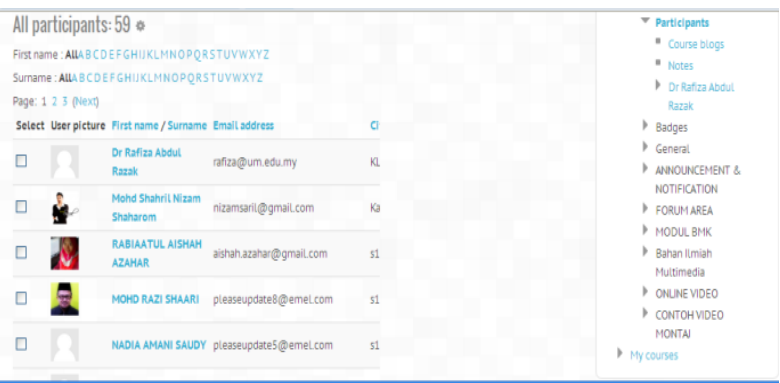

Fig. 1. Teachers participated in the virtual training.

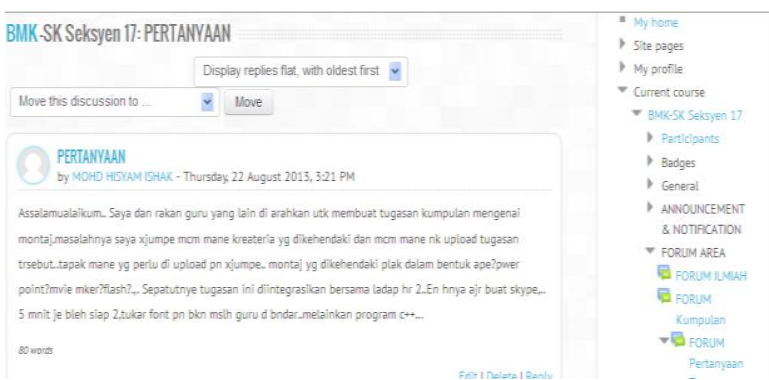

Fig. 2. Inquiries posted by teachers.

Step 2: Honorarium and certificates.

Trainers should encourage teachers to participate in the virtual training, and the school administration also played an important part in providing such encouragement. For motivational purposes, trainers provided certificates signifying participation in the entire program and, as further encouragement, an honorarium was also given to each participant.

Step 3: Guide.
Step-by-step guidance was requested byparticipants to help withsome difficulty in accessing the virtual training platform. Assistance at the computer laboratory was also given to teachers having difficulty in logging in. This was the first stage of involvement in the virtual environment.

\section{B. Content Analysis}

Step 4: Participation.

Teachers began to participate in the virtual training environment as shown inFig. 1.

Step 5: Feedback.

Teachers posted inquiries to trainers throughout the virtual training process.Interaction between trainer and teachers are illustrated in Fig. 2, Fig. 3 and Fig. 4.

Step 6: Production of instructional materials.

Some groups submitted the instructional materials in a video format online via YouTube. Fig. 5 is an example of online instructional materials in the form of video produced by a particular group of teachers.

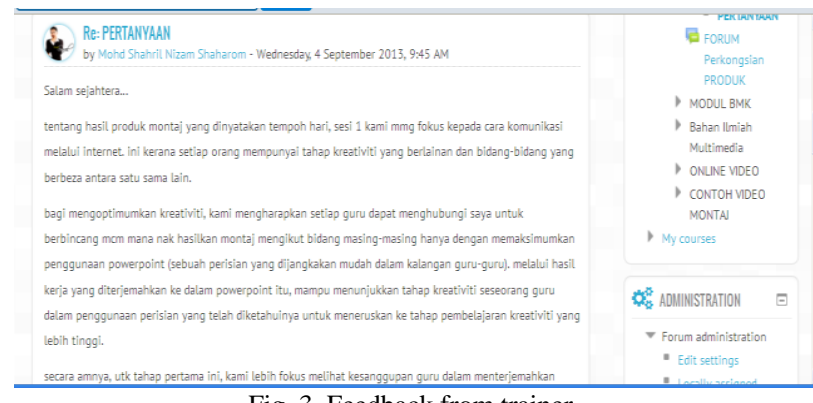

Fig. 3. Feedback from trainer.

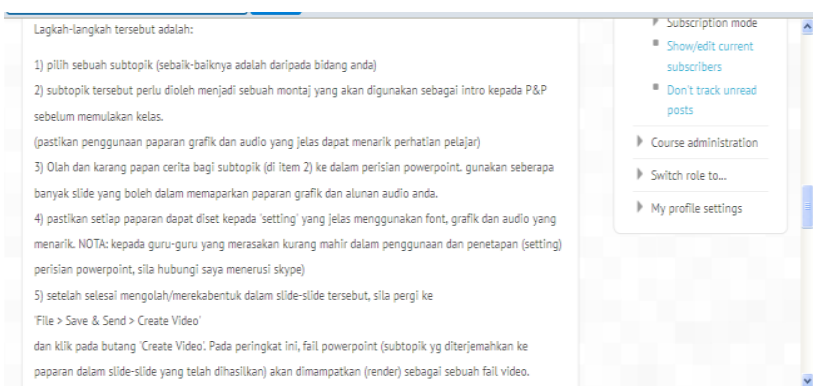

Fig. 4. Feedback from trainer.

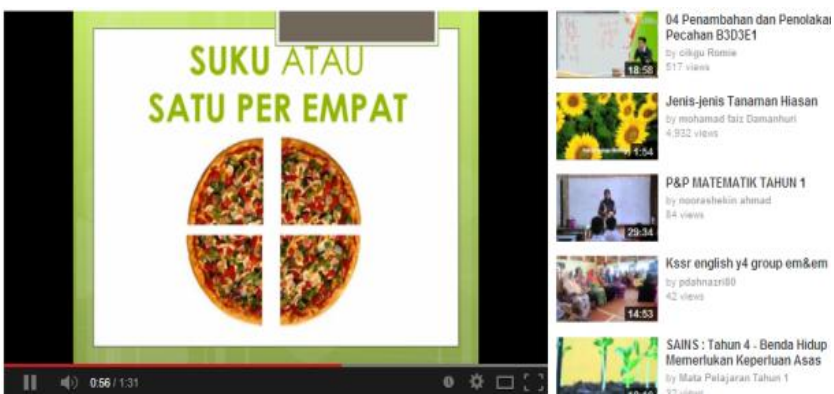

Fig. 5. Instructional material created by a group of teachers.

\section{RESEARCH IMPLICATIONS}

A system design based on the analyses describedfor management of virtual training for teachers was produced as illustrated in Fig. 6. The training environment was divided into two parts: authentic and virtual. The diagram of Fig. 6 is presentedin the form of a pyramid to show the hierarchical relationshipsinthe training process.

In an authentic training environment, the initial activityis a 
practical stage embodied by the face-to-face training session. Face-to-face training is a preparatory stage before experiencing virtual training [17], [18]. The next level, still within the authentic training environment, is labeled as the motivation stage.This provides essential strong encouragement for teachers to continue participation atthe next level involving the virtual training environment [19].

The understanding stage is the first level of the virtual training environment. At this stage, the teachers were assisted and closely guided to ensure that they all signedonas participants inthe virtual training andwere able to proceed onto the next level, the application stage. At this pointteachers explore and discover mediaof interaction and communication via e-collaboration [20]. They share their thoughts and opinions and thus reflect on their experience.

The final level is described as the synthesis stage.Eventually the teachers produce instructional materials via online video, thereby not only gaining pedagogical knowledge and practice but also experiencing virtual instruction [21].

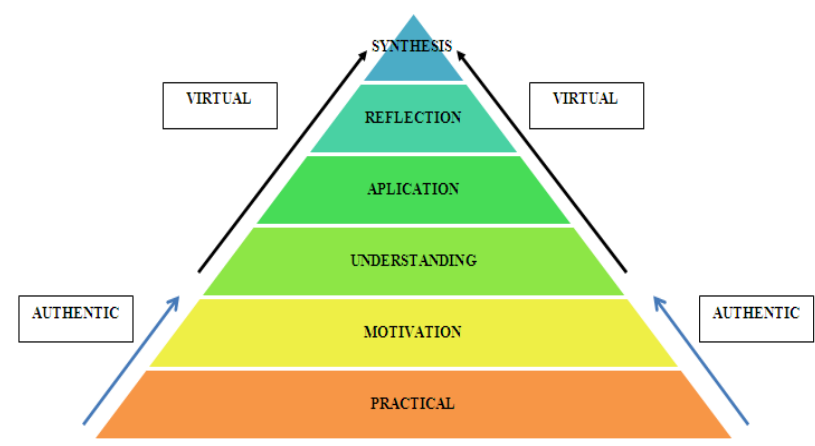

Fig. 6. System design for management of virtual training for teachers.

\section{CONCLUSION}

Ref. [22] statedthat educational institutions are increasingly challenged to develop more and more virtual instruction. Developing professional virtual training is cost-effective,fast, andefficient indelivering practical educational training. The designed management system is effective anduseful and is recommended for future application in designing virtual training for teachers.

\section{ACKNOWLEDGMENT}

The authors wish to thank the teachers involved in e-CPD. This work was supported in part by a grant from the University of Malaya Research GrantNo.RP002C-13ICT.

\section{REFERENCES}

[1] British Educational Communications and Technology Agency (Becta) (2004). A review of the research literature on barriers to the uptake of ICT by teachers. [Online]. Available: http://www.becta.org.uk

[2] F. D. Yusop, R. A. Razak, and S. M. M. A. Basar, "Social media for social advances: use of social media in educating future generations," in Social Networks: Issues and Challenges, A. Sulaiman, Ed., Singapore: Patridge Publishing, 2014, ch. 5.

[3] S. Al-Senaidi, L. Lin, and J. Poirot, "Barriers to adopting technology for teaching and learning in Oman," Computers \& Education, vol. 53, no. 3, pp. 575-590, 2009 .

[4] K. A. Bingimlas, "Barriers to the successful integration of ICT in teaching and learning environments: a review of the literature,"
Eurasia Journal of Mathematics, Science \& Technology Education, vol. 5, no. 3, pp. 235-245, 2009.

[5] P. A. Ertmer, "Addressing first-and second-order barriers to change: strategies for technology integration," Educational Technology Research and Development, vol. 47, no. 4, pp. 47-61, 1999.

[6] J. VanBraak, "Factors influencing the use of computer mediated communication by teachers in secondary schools," Computers \& Education, vol. 36, no. 1, pp. 41-57, 2001.

[7] UNESCO. (2008). ICT competency standards for teachers: policy framework. [Online]. Available: http://unesdoc.unesco.org/images/0015/001562/156210E.pdf.

[8] A. Kennedy. (2005). Models for continuing professional development: a framework for analysis. Journal of In-Service Education. [Online]. 31(2), pp. 235-250. Available: http://www.library.dcu.ie/Eresources/databases- az.htm.

[9] F. K. Olakulehin. (2007). Information and communication technologies in teachertraining and professional development in Nigeria. Turkish Online Journal of Distance Education. [Online]. 8(1). Available: http://tojde.anadolu.edu.tr/tojde25/pdf/article_11.pdf.

[10] C. Hague and B. Williamson, "Digital participation, digital literacy, and school subjects: a review of the policies, literature and evidence,' Futurelab, August 2009.

[11] H. Becker and M. Riel, "Teacher professional engagement and constructivist-compatible computer use," Teaching, Learning, and Computing: 1998 National Survey, Report No 7, 2008.

[12] Learning and Skills Network. (2007). A professional development framework for e-learning. [Online]. Available: http://www.niace.org.uk/exemplars/pdf/0627161Framework.pdf

[13] M. Kirkwood et al., "The new opportunities fund (nof) ict training for teachers programme: designing a powerful online learning environment," presented at the European Conference on Educational Research. Edinburgh, UK, September 20-23, 2000.

[14] R. M. Gagne, The conditions of learning, New York: Holt, Rinehart and Winston, 1965.

[15] R. Snoeyink and P. A.Ertmer, "Thrust into technology: how veteran teachers respond," Journal of Educational Technology Systems, vol. 30, no. 1 , pp. $85-111,2002$.

[16] W. Veen, "How teachers use computers in instructional practice - four case studies in a Dutch secondary school," Computers \& Education, vol. 2, no. 1, pp. 1-8, 1993.

[17] K. SitiNorazlina, "Barriers in computer and ICT utilization in teaching and learning among teachers in rural secondary schools in Kulai Jaya Johor," Mastersthesis, Faculty of Education, University of Technology Malaysia, Malaysia, 2008.

[18] M. J. O. D. Lukman, "Islamic education teachers' perception on the use of ICT," Journal of Technical, Vocational \& Engineering Education, vol. 4, December 2011

[19] C. Bosley and S. Moon, "Review of existing literature on the use of Information and Communication Technology within an educational context," Centre for Guidance Studies, University of Derby, 2003.

[20] A. Wilson, S. Rimpiläinen, D. Skinner, C. Cassidy, D. Christie, N. Coutts, and C. Sinclair, "Using a virtual research environment to support new models of collaborative and participative research in Scottish education," Technology, Pedagogy and Education, vol. 16, no. 3, pp. 289-304, 2007.

[21] S. Dash, R. Q. Kramer, L. M. O’Dwyer, J. Masters, and M. Russell, "Impact of online professional development on teacher quality and student achievement in fifth grade Mathematics," Journal of Research on Technology in Education, vol. 45, no. 1, pp. 1-26, 2012.

[22] J. Gregory and G. Salmon, "Professional development for online university teaching," Distance Education, vol. 34, no. 3, pp. 256-270, 2013.

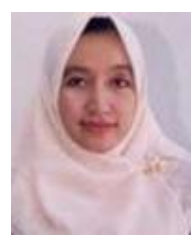

Rafiza Abdul Razak is a senior lecturer at the University of Malaya, Kuala Lumpur, Malaysia. She holds a PhD with specialization in instructional design and technology and has ten years of experience as a lecturer at the University of Malaya and five years of experience in a secondary school.

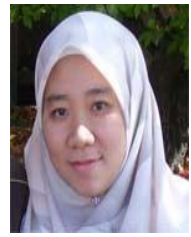

Farrah Dina Yusop is a senior lecturer at the University of Malaya, Kuala Lumpur, Malaysia. She received a PhD in 2010 from Iowa State University (ISU), USA, in the fields of curriculum and instructional technology (CIT) and human computer interaction (HCI). She has published more than 50 journal and conferencepapers. She actively conducts research and publishes in the areas of 
civic-minded instructional designer (CMID) conceptual framework, teaching and learning in higher education contexts, Web 2.0, social media, educational games, and mobile learning

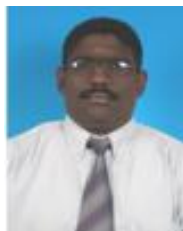

Yugendren Perumal specializes in instructional design and technology. He has been working as a teacher at a Malaysian primary school for the past four years. He is in the process of completing his master's degree in the area of instructional technology at the University of Malaya, Malaysia.

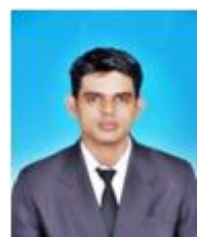

Sri Raman Chukumaran specializes in instructional design and technology. He has been working as a teacher at a Malaysian Tamil Primary School for the past four years. He is in the process of completing his master's degree in the area of instructional technology at the University of Malaya, Malaysia. 